\title{
EL DORADO ILUSTRADO: LAS EXPEDICIONES ESPAÑOLAS AL PARIME (GUAYANA). 1770-1777
}

\author{
POR \\ EMANUELE AMODIO \\ Escuela de Antropología Universidad Central de Venezuela Caracas
}

Se estudian las penetraciones europeas en el interior de la Guayana venezolana, entre los ríos Uraricuera y Branco, próxima al lago Parime -una región dónde solia situarse al mitico Dorado-. Asimismo se destaca la geoestrategia española de la Ilustración, siguiéndose con pormenor las actuaciones del gobernador de Guayana (Manuel Centurión) dentro de aquella politica: expediciones para expulsar a portugueses y la fundación de varios pueblos en la zona, con el fin de consolidar la frontera.

\section{INTRODUCCIÓN}

El conocimiento de América por parte de las sociedades europeas estuvo determinado, a lo largo de la conquista, por una mezcla de referentes míticos europeos sobre todo geográficos y datos empíricos del nuevo territorio, acumulados a través de la experiencia. Para Colón el nuevo continente era el Katay y la cartografía incipiente del Caribe fue expresión de esta confusión y del intento de encontrar una coherencia entre los datos geográficos reales y los míticos, derivados de los viajes europeos mas o menos fantásticos hacia el Oriente (Marco Polo, sobre todo).

Una vez que los españoles llegaron a la conclusión que se trataba de un nuevo continente, la búsqueda del conocimiento geográfico encuentra su fuente principal en los pueblos indígenas

SIGLAS UTILIZADAS:

AGI: Archivo General de Indias, Sevilla.

AGNC: Archivo General de la Nación, Caracas.

AGS: Archivo General de Simancas.

MN: Museo Naval, Madrid. 
de la región. Sin embargo, este conocimiento indígena no respondía totalmente a la lógica del saber empírico, sino que era también fruto de la exigencia de control cultural del territorio y, por ende, estaba mezclado con elementos míticos característicos de cada grupo étnico: ideas del centro del mundo, espacios míticos subterráneos, regiones pobladas por monstruos, etc.

En el marco de la conquista del Nuevo Mundo, la búsqueda del oro marcó desde el «descubrimiento» la avanzada española. Es este «sueño del oro" el que determinó en buena parte la construcción geográfica del continente americano. Así, las tierras americanas acabaron siendo el escenario donde los europeos representaron sus mitos y sus deseos: desde el "Paraiso terrenal», hasta las tierras de monstruos y minas de oro (1).

Los indigenas caribeños indicaban la Tierra Firme como lugar del oro, y los de Tierra Firme, a su vez, desplazaban todavía más ese lugar hacia la selva profunda. Así, de la mezcla cultural de elementos indígenas y españoles nace una historia: El Dorado, mítico rey de Manoa, la ciudad del oro. En un primer tiempo el reino de El Dorado fue situado en los territorios andinos de la actual Colombia, bajo la influencia de las noticias que los españoles obtuvieron sobre los muiscas y, al mismo tiempo, trás de la leyenda de la huida de los incas cuzcueños hacia las selvas del mítico Paititi. Sin embargo, ya desde las primeras décadas del siglo XVII se mira a la desconocida Guayana como sitio ideal para la colocación geográfica del mítico reino. Así, en la representación geográfica de Guayana aparece, tempranamente, la imagen de un gran lago (el Parime) en cuyas riberas se encontraría la ciudad de Manoa. Conocimiento imaginario y noticias indígenas se mezclan para construir el mito que dio pie a la mayoría de las expediciones europeas hacia las regiones delimitadas por el Orinoco y el Amazonas y sus signos invaden la literatura y la cartografía producidas a lo largo de toda la época colonial.

Las últimas expediciones hacia el Parime fueron organizadas por el Gobernador de Guayana don Manuel Centurión entre 1773 y 1775 y generaron el conflicto con los portugueses que avanzaban desde el río Amazonas. Estas últimas expediciones dejaron en claro que en esas regiones no había ninguna ciudad y que el lago Parime era sólo un mito de la conquista del Nuevo Mundo. Cuando españoles y portugueses se encuentran violenta-

(1) Emanuele Amodio, Formas de la alteridad Construcción y difusión de la imagen del indio americano. Quito, ed. Abya Yala, 1993. 
mente en el río Branco, se acaba el espacio desconocido, representado como infinito, tierra de los sueños y de las posibilidades. En el nuevo espacio geográfico, empíricamente determinado no hay ya lugar para míticos lagos de oro y el sueño se desvanece rápidamente.

\section{El contexto históRICo De las eXPediciones al PaRime}

La región que llamamos Guayana presenta una peculiaridad dentro de la conquista de América: primera región en ser descubierta y una de las últimas en ser conquistada. Podemos indicar por lo menos dos causas que explican esta situación: (a) las características geográficas que hicieron difícil la conquista y (b) la presencia de poblaciones indígenas que mantuvieron fuerte resistencia a tal penetración. Nos referimos, particularmente, a la oposición caribe que dificultó por casi tres siglos la avanzada española hacia las regiones interiores de Guayana.

Durante dos siglos los españoles intentan estabilizar la conquista del Orinoco, sin mucho éxito. Diego de Ordaz (1531), Fernando de Serpa (1549), Lope de Aguirre (1561), Diego de Serpa (1568), son sólo algunos de los nombres que marcaron este intento de conquista en el siglo XVI. Sin embargo es con Antonio Berrío y sus tres expediciones (1591-1595) que Guayana adquiere verdadera identidad histórica y "El Dorado» encuentra su definición "geográfica». Escribe Berrío: «...en la cordillera hay una laguna grandísima, y que de la otra parte de ella ay grandes poblaciones y muy gran número de gente y gran riqueza de oro y de piedras" (2). Al lado de Berrío debe citarse también el intento del inglés Walter Raleigh (1595), particularmente importante para la difusión de las noticias de la existencia del reino de El Dorado, cerca del lago Parime (3). De hecho, es con éste que el lago Parime hace su aparición oficial (cfr. el mapa de Walte Raleigh de 1595).

Así, desde esta época, nuevos europeos se adelantan en dirección de Guayana: los ingleses, tras los mitos de Raleigh, seguidos por los corsarios del Caribe y, ya en el siglo XVII, por los holandeses con su Compañía Holandesa de las Indias Occidentales (1621). También los franceses se acercan a Guayana a mitad del 1600 y los portugueses a mitad de ese siglo, por el río Amazonas.

(2) Antonio Berrío, "Carta al Rey de España" (1585). En Pablo Oier, La Formación del Oriente venezolano, Caracas, ed. UCAB, 1966, pág. 494.

(3) Cfr. Walter RALEIGH, El descubrimiento del grande, rico y bello imperio de Guayana. Caracas, ed. Juvenales Herrera, 1986. 
Los eventos europeos de la primeras décadas del siglo XVIII apuntan el interés de las naciones sobre el Caribe y Tierra Firme, produciendo un renovado intento de parte de España y Portugal de extender su conquista. Además, en el contexto del naciente pensamiento ilustrado, se avanzan hipótesis de un nuevo tipo de ocupación de los territorios guayanenses: la ocupación de nuevos territorios dirigida directamente por el Estado; la eliminación de intermediarios (particulares o misioneros); y una organización «moderna" de las instituciones locales: Gálvez, para España, y Pombal, para Portugal, pueden ser considerados los autores de tales políticas. Del lado español, será la expedición de límites al mando de Iturriaga (1754), organizada después del Tratado de Madrid entre España y Portugal (1750), la que intentará realizar tales planes (4).

Los años de permanencia de Iturriaga en el Orinoco fueron dedicados a estabilizar la conquista y a reducir de una vez por todas a los rebeldes caribes. Es frente a esta ofensiva que buena parte de los caribes del medio Orinoco se desplaza paulatinamente hacia las regiones de los ríos Branco y Esequibo.

Don Manuel Centurión, sucesor de Iturriaga en la Comandancia de Nuevas Poblaciones (1767), será el verdadero realizador de los planes de Gálvez, gracias también al poder derivado de la asunción contemporánea de la Comandancia Interina de la Provincia de Guayana (5). Además, esta Comandancia, ya dependiente del virreinato de Santa Fe, pasa a depender del Capitán General de la provincia de Venezuela, Don José Solano, quien había sido uno de los comandantes de la expedición de límites. El 5 de mayo del 1768, una real cédula transforma las dos comandancias en una única gobernación, ratificando al mismo tiempo el nombramiento de Centurión hecho por Iturriaga (6).

La obra del comandante Centurión en Guayana puede ser resumida en tres puntos fundamentales: organización de la defensa del Orinoco, particularmente a través de la fundación de aldeas españolas; contrarrestar la avanzada de los holandeses y mantener activa la lucha contra los caribes. Prácticamente se trata del mismo plano de Iturriaga, readaptado a la evolución de la situación política local y, también, internacional.

(4) Manuel LuCEnA Giraldo, Laboratorio tropical La expedición de limites al Orinoco, 1750-1767. Caracas, ed. Monte Avila/CSIC, 1993.

(5) AGNC, La Colonia, Papeles de Centurión, n 2, ff. 18-19.

(6) Cfr. M. I. González del Campo, Guayana y el Gobernador Centurión. Caracas, ed. Academia Nacional de la Historia, 1984, pág. 84. 
La realización de los planes de Centurión encuentran en los misioneros capuchinos escasa colaboración y, en algunos momentos, oposición explícita. De cierta manera, la contraposición es sobre todo ideológica: dos visiones del mundo americano (civil y religiosa) se contraponen y cada una de las partes tiene suficiente poder para intentar imponer su idea a la otra. Centurión, dedicado a organizar un poder civil y militar en Guayana, mal soporta la autonomía misional en los pueblos de Misión donde, según el comandante, «...los Indios sin comercio, y ejemplo de españoles se mantienen retirados en sus Pueblos, casi tan desnudos, bárbaros, e inútiles al estado, como eran cuando vivían en las selvas antes de su reducción" (7).

Los misioneros, por su parte, se resistían a entregar los pueblos de misión al poder civil por no considerar todavía kaptos" a los indígenas. Además, rechazan el control civil sobre las misiones y, naturalmente, estaban reacios a pagar los diezmos impuestos por Centurión. En 1774 los capuchinos consiguen una real cédula que ordenaba a Centurión sacar a los Corregidores de los pueblos de misión. Además, parece ser que a ellos se debe también la salida de Centurión en 1777.

Esta situación de polémica entre la institución civil local y la religiosa debe ser considerada el trasfondo de los eventos que nos aprestamos a relatar. De hecho, no sólo cada uno intentará, por su cuenta, llegar al Parime, sino que la misma posibilidad de participación capuchina en una de las expediciones de Centurión fallará aun antes de comenzar.

A parte de la búsqueda de El Dorado, otros elementos de orden más realista impulsan a Centurión a organizar la avanzada hacia el lago Parime. Se trata de la llegada activa de holandeses y portugueses al escenario guayanense cercano a los establecimientos españoles (8). De cualquier manera, aun no subestimando completamente el peligro holandés, Centurión lo relega en un segundo plano, estando consciente que el verdadero peligro reside en la avanzada lusitana (9).

(7) “Consejo de Indias: Relación al Rey sobre pedidos de Centurión" (22 de abril de 1774). AGI, Caracas, 13.

(8) "Director General del Esequibo: Carta a la Compañía de las Indias Occidentales" (Agosto de 1764). Citada por Nadia FARAGE, As Muralhas dos Sertøes: os Povos Indígenas no Rio Branco e a Colonizaçio. Campinas, Tesis de Post-grado en Ciencias Sociales, Universidad de Campinas (Brasil), 1986, pág. 125.

(9) "Manuel Centurión: Carta al Virrey", 3 de noviembre de 1770. En González del Campo [6], pág. 366. 


\section{El acercamiento al Parime}

El progresivo acercamiento a la región del Parime, no fue sólo dictado por la búsqueda del Dorado. Poco a poco, el proyecto doratista se había ido transformando y la mítica Manoa ya se trasmutaba en algo más real. El oro y la plata existían verdaderamente (10), pero su colocación era del tipo tradicional: las minas y los ríos. En este sentido, es muy interesante la actitud de Alvarado, integrante de la Expedición de Límites (1754), cuando aconseja a los misioneros «sepultan" las minas esperando tiempos mejores para su explotación:

Esta recomendación de sepultar [callar la existencia de] las minas, fue tomada muy en cuenta, tanto por los capuchinos como por los gobernantes de Guayana que, en los años subsiguientes, jamas hicieron alusiones públicas al oro de las misiones, pero eso no impedía la proliferación de los rumores. Los Caribes y los otros indios de las misiones conocían perfectamente el secreto y lo propagaban a los cuatro vientos, de modo que no tardó en llegar a oídos de los holandeses de Esequibo. La última fase de las guerrillas caribes contra los españoles estuvo íntimamente relacionada con la codicia holandesa por el oro de los capuchinos. Además, se produjo una pugna entre los frailes y las autoridades civiles españolas en relación con el control del territorio aurífero, pugna que culminó en tiempos del Gobernador Centurión (11).

Por otro lado, la necesidad para los españoles de adelantar la conquista era determinada por la presencia holandesa y portuguesa. Se trata pues de llegar antes que ellos y ocupar poblando.

$\mathrm{El}$ intento del fraile observante Ximenez Borrego puede ser considerado uno de los primeros para aproximarse al Parime (1753-1754). Con un plan para repoblar el río Aro, Borrego persigue al jefe caribe Oroparena, con la aprobación de la Gobernación de Cumaná. Para conseguir capturar a los caribes, Borrego proyecta una expedición a la Paragua, pero tal propósito encuentra la oposición de Caulín, ya que se preparaba la de Iturriaga a la cual el mismo Caulín se incorporará como Capellán (12). De

(10) Arenillas "plateadas" fueron encontradas por doquiera y no siempre contenian oro o plata.

(11) Marc de Civrieux, "Los Caribes y la conquista de la Guayana española (Etnohistoria Kari'ña)". En Montalban, n² 5: 875-1021. Caracas, 1976, pág. 951.

(12) Civrieux [11], pág. 954. 
hecho, consigue disuadir a Borrego y mantenerlo cerca del río Aro, área de tránsito de los caribes fugitivos de las misiones.

La expedición de Borrego es prácticamente substituida por la de Iturriaga, quien impulsa el reconocimiento de los cursos de los ríos que desaguan en el Orinoco, consiguiendo así, por ejemplo, remontar el río Caroní hasta sus fuentes. Caulín, que acompaña la expedición, toma nota del recorrido del Caroní y de que su nacimiento está ubicado cerca del río Parime. Otra expedición de reconocimiento consigue remontar un trecho del Paragua, de donde regresan a la misión de Morocori (13).

Estas expediciones permiten ya vislumbrar una posible vía de acceso al Parime. Además, los datos recopilados por Iturriaga y Caulín, son confirmados ampliamente por las descripciones indígenas: el Caura y el Paragua son las vías de acceso «natural» al centro de la región (14). Este conocimiento indígena era sobre todo resultado de la existencia de grandes redes de intercambio intertribal que se extendian por todo el territorio guayanense, atravesado en su totalidad por las rutas de los "mercaderes" de corta y larga distancia (15). La ruta que más nos interesa es la que unía el área Caura-Paragua con la del Parime. Los caribes remontaban el Caura (o Caroní) llegaban al caño Poruspo a través del cual pasaban al Paragua. Aquí la ruta se dividía en dos ramales: un brazo conducía al Ventuari y el otro bajaba por el Uraricoera (Parime). Como escribe Marc de Civrieux, klas piraguas remontan el río Paragua hasta sus fuentes, atraviesan la Sierra Parime (hoy Pacaraima) y llegan al río Parime (hoy AuariUraricoera) (16). Una vez en el Uraricoera, navegaban hasta la confluencia con el río Tacutú y desde aquí era fácil pasar al Rupununi, a través del pequeño río Pirara (17). El mapa del anexo $n^{2} 1$ indica gráficamente esta ruta.

Hay que señalar que son los mismos capuchinos, en particular el padre De La Bisbal, quienes proponen a Iturriaga (1758) un

(13) Idem, págs. 956-957.

(14) "P. Narciso de La Bisbal: Carta a Iturriaga", 19 de septiembre de 1758. MN, Ms. 565, ff. 299-300.

(15) Sobre los "mercaderes" indígenas, Karl Polany, K (ed.), Comercio y mercados en los imperios antiguos. Ciudad de México, ed. Labor Universitaria, 1976.

(16) Demetrio Ramos PÉrez, Estudios de Historia Venezolana Caracas, ed. Academia Nacional de la Historia, 1988, pág. 628.

(17) "Fr. José de Magdalena: Carta al Gob. Mendonça Gurjao", 25 de junio de 1750. En VV.AA., Question de la frontière entre la Guyane Britannique et le Brésil. Annexes au Mémoire Présenté par le Gouvernement de Sa Majesté Britannique. Londres, 1903, vol. III, pág. 188. 
análisis de los errores cometidos en esta búsqueda española y la necesidad de utilizar la información indígena:

Si piensan los holandeses al comercio de Barinas por el río Caura, pasando a éste por el Parime para excusar el paso de la Angostura es señal de la proximidad de las cabeceras del Caura al curso del Parime. Dejando a parte los pensamientos de los holandeses que totalmente ignoro, digo que, según noticia no son muy lejos las cabeceras del Caura al curso del Parime, aunque, pasada la boca del Curaricapara para arriba, hay muchos saltos. Espero en breve un indio hijo de aquellos parajes, y no es caribe, que está casado en esta misión, que me dará noticia de todo aquello del río Caura, del paso de éste a la Paragua y la distancia de las cabeceras del Caura, al curso del Parime, para que pueda yo comunicarle a VS. (18).

Aparte de la posibilidad de acceso al Parime representada por el Caura-Paragua, existía otra en la representación geográfica española de este siglo. La imagen del famoso lago, desde el siglo XVII, conllevaba una cordillera de montañas a sus alrededores, que harian difícil el acceso (19). Es decir: era necesario acercarse al lago desde la kextremidad» de dicha cordillera. Al sur, tal extremidad estaría representada por el acceso Caura-Paragua; al noroeste, al otro extremo, por el Esequibo (cfr. el mapa de D'Abbeville de 1656). Sin embargo, éste era controlado por los holandeses $o$, al menos, su presencia cercana junto a la de los caribes, impedía la utilización de tal acceso.

A pesar de ello, por lo menos un intento fue realizado por parte de los misioneros capuchinos catalanes. Aparte de la fundación de la misión del Cuyuní con indios guaicas, sabemos de una expedición misional al Rupununi en 1758, guiada por Fray Benito de la Garriga (20). No sabemos si este misionero llegó cerca de la región del Parime, pero su descripción del viaje permite una hipótesis afirmativa (21). Será este mismo Fray Be-

(18) P. Narciso de La Bisbal: Carta a Iturriaga, (27 de agosto de 1778). En B. Carrocera, (ed.). Misión de los Capuchinos en Guayana. Caracas, ed. Academia Nacional de la Historia, 1979, vol. 1, pág. 372.

(19) Sobre el valor mítico de cordilleras y montañas en el imaginario español, Lilia LITVAK, L., El ajedrez de estrellas. Barcelona, ed. Laia, 1987, pág. 27.

(20) Manuel Donis Rios, Evolución histórica de la Cartografía en Guayana y su significación en los derechos venezolanos sobre el Esequibo. Caracas, ed. Academia Nacional de la Historia, 1987, pág. 118.

(21) Manuel Donis Ríos, "Significación del Mapa Geográfico de América Meridional de Juan de La Cruz Cano y Olmedilla en la Historia Cartográfica de Guayana". En Montalban, n 16: 105-131, Caracas, pág. 119 
nito de la Garriga quien intentará en 1772 llegar al Parime por el acceso más seguro del Caura.

\section{El «PRoyecto Parime» De Manuel Centurión}

En 1770 el proyecto de Centurión de llegar al Parime se hace público y se formaliza. Centurión despliega una amplia actividad "publicitaria" a través de cartas al Virrey, al Consejo de las Indias, a Solano, etc., explicando sus planes, justificándolos con la amenaza portuguesa, dejando imaginar el oro del Parime $y$, sobre todo, pidiendo dinero para su expedición: «pero, como he dicho antes, me faltan medios para continuar estos progresos, y apenas podré sostener y conservar lo ya hecho si no se me franquean auxilios para ello" (22).

Es de suma importancia describir la estrategia que Centurión quiere adoptar para llegar al Parime, por ser ésta la que le permite justificar mejor su pedido de recursos. Centurión no piensa llegar de una vez al Parime, con una sóla expedición. Sabe que este tipo de empresa necesita un acercamiento progresivo, a través de la fundación de pueblos intermedios. En una «Relación del Consejo de Indias al Rey» de 1774 sobre los planes de Centurión y sus pedidos financieros, se lee textualmente que «no tienen gente, con que ocupar los precisos tránsitos con Pueblos, que les sirvan de escala, para penetrar el País, y llegar a establecerse en la Famosa laguna Parime»... (23). De esta manera, Centurión piensa conseguir dos resultados: ocupar la región de la banda sur del Orinoco y, utilizando estas nuevas aldeas como escala, llegar con mayor facilidad al Parime (24).

El plan de Centurión no es simple, ya que múltiples son las finalidades que quiere alcanzar. Antes de todo, se trata de "contener a los portugueses que se van acercando a ella [la laguna] y ganando terreno a toda prisa" (25). En segundo lugar, ya que en esa región están refugiados los indígenas fugitivos del Orinoco, se intentará reconducirlos nuevamente a sus pueblos de misión respectivos. El razonamiento de Centurión, tal vez demasiado

(22) Manuel Centurión: Carta al Consejo de Indias (20 de abril de 1771). En Carrocera [18], vol. II, pág. 134.

(23) Consejo de Indias: Relación al Rey, 22 de abril de 1774. AGI, Caracas,

(24) Antonio Caulín, Historia de la Nueva Andalucía Caracas, ed. Academia nacional de la Historia, 1987, vol. I, pág. 105.

(25) Manuel Centurión: Carta al Consejo de Indias, 20 de abril de 1771. En CARROCERA [18], vol. II, pág. 134.

R. I., 1995, $\mathrm{n}^{\circ} 203$ 
confiado, es el siguiente: en las «islas, márgenes, caños y vertientes, se hallan bastantes indios, para poblarlas, y sobrarán entonces para las orillas de Orinoco, porque los mismos que la abandonaran por huir de los españoles, viéndonos allá dentro y que no tienen ya a donde esconderse de nosotros, sino el inconveniente de dar en las manos de otros europeos que no los tratan bien, volverán luego a disfrutar entre nosotros la abundantísima pesca y singulares conveniencias de este ríon (26). Como veremos, la reacción indígena a la llegada de los españoles, por lo menos de los que se habian fugado, fue de tipo bien diferente, sobre todo si tenemos en cuenta la versión capuchina de los hechos.

Finalmente con esta expedición, Centurión quiere también conseguir el bloqueo de los holandeses. Ya vimos que esta área era utilizada por los caribes como "reserva" para la captura de "esclavos» destinados al mercado holandés. Centurión pretende provocar una crisis en el abastecimiento de mano de obra para las plantaciones holandesas y por ello se hace importante controlar esa región.

Para resumir todas estas características del "proyecto Parime» de Centurión, citamos un párrafo de una carta enviada al Virrey el 3 de noviembre de 1770:
Abriremos la entrada para el progreso de nuestras misiones, antes que los extranjeros se apoderen del país, o nos lo despue- blen con la continua extracción de indios que esclavizan para el incremento y agricultura de sus colonias, por medio del cruel infame comercio de poitos con los caribes. Contendremos dentro de sus limites a los holandeses de Esequibo, Bervis y Surinami franceses de la Cayena, y portugueses de Amazonas, estando a la mira para embarazarles las usurpaciones que hacen constan- temente en estos nuevos dominios, sin que ahora las podamos evitar, y asegurando al Rey la posesión de este precioso y dilatado país" (27).

La referencia a las misiones es aquí, a todas luces, una justificación de circunstancia, siendo otros muy distintos los planes de Centurión. Sin embargo, tales afirmaciones encontrarán inesperada realización (o por lo menos el intento): los capuchinos organizan una expedición antes del comandante y sin su conocimiento.

(26) Ibídem, pág. 133.

(27) Manuel Centurión: Carta al Virrey de Santa Fe, 3 de noviembre de 1770. En GONZÁlEZ DEL CAMPO [6], 1984, pág. 365. 


\section{La EXPEdición CAPUChINA al PaRime (1772)}

El 15 de mayo de 1772, el padre capuchino Benito de la Garriga, junto al P. Tomás de Mataró, 14 españoles, y un grupo de indígenas, dan inicio a una expedición hacia el Parime. Esta decisión de los capuchinos tiene la finalidad explícita de adelantarse a Centurión y a los misioneros observantes. Escribe el padre de la Garriga a su vuelta:

El motivo de haber ido nosotros a la Parime es que el mes antes de salir, el Comandante de esta provincia envió un destacamento con dos Padres observantes para hacer misiones en el Parime y por no perder nosotros la posesión de aquellas tierras que por la concordia nos pertenecen, según los mapas que ponen la laguna de Parime más a Este que al Sur, pedí licencia a los RR. Padres para ir y llegar primero que ellos ... Dichos Religiosos observantes se detuvieron enfermos mucho tiempo en el río Erevato de Caura, en que tienen un pueblo dichos Padres, por donde tenían orden de entrar a la Parime y tuvieron noticia que era muy dificultoso o imposible lograrlo (28).

Los capuchinos se embarcan en la misión de Auguri (Guri) y un mes y medio después de su salida, la expedición deja el Caroní para entrar en el río Icabaru (cfr. mapa anexo 2). Desde aqui, después de siete días de navegación, entran en las "sabanas del Parime», ya cerca del río Mayarí (29).

El padre de La Garriga describe las poblaciones indígenas, que encuentra con una percepción muy aguda de sus costumbres anotando sus vestimenta y sus armas, etc. Lo que parece más asombrar al padre, es el gran número de indígenas que vivían en esas sabanas:

Desde la misma boca de la Paraua todas estas tierras hasta Mayarí y las que se dejen a la izquierda hasta Esequibo, toda la tierra está regada de naciones. En el dicho camino hallé Barinagotos, Cucuigotos, Ipurugotos, Mapisanas, y éstos sin salir de la orilla del río Caroní e Icabaru (30).

(28) P. Benito de La Garriga: Carta al P. Comisario General de las Misiones, 3 de noviembre de 1772. En CARROCERA [18], vol. II, pág. 178.

(29) "Tomás de Mataró y Benito de la Garriga: Viaje por los rios Caroní, Icabaru, Sierra de Pakaraima hasta las sabanas del rio Parime" (1772). En Cesareo de Armellada, Por la Venezuela de ayer y de Hoy. Caracas, ed. La Salle, 1960, págs. 118-142.

(30) Ibidem, págs. 138-139. 
De estos indios, algunos son caribes fugitivos de las misiones capuchinas del Orinoco. Tal vez, sea éste el hecho que provocará el desastre. El día 8 de marzo la expedición es asaltada simultáneamente con «flechas y escopetadas" por los saparás y los paravillanes, desde los dos lados del río Mayarí. Resultan muertos nueve caribes que acompañaban a los frailes y un civil español. El padre Tomás es herido, pero no gravemente. Durante el ataque un mulato y seis caribes de la expedición se escapan volviendo atrás y anunciando la muerte de los padres y el fracaso de la expedición (31).

Sin embargo, los hechos eran otros: después del asalto de los indígenas resultaba difícil para los padres convencer a los españoles y a los caribes sobrevivientes a quedarse y continuar. Además, otro grupo de expedicionarios se escapa y termina naufragando en el río (dos españoles mueren), mientras el resto de la expedición continúa a pie por la sabana. Luego de 15 días, bajo el peligro de ser atacados nuevamente, consiguen construir unas curiaras de cáscara y regresan a la misión de Auguri, donde llegan el cuatro de julio.

Sobre las causas del fracaso tenemos ya la hipótesis de los mismos misioneros: son los caribes fugitivos de las misiones quiénes estaban detrás del asalto a la expedición. Esta hipótesis es confirmada por la presencia de dos jefes caribes del Orinoco en las montañas del Caura, cerca del Uraricoera (área sapará): Tumurúde Murucurí y Mayaracán de Cunurí. Este último es acusado de haber matado al padre Anastasio de Olot, en una de las expediciones al Paragua. Es el mismo padre La Garriga quien relata la presencia y el papel desempeñado por Mayaracán: «supimos también que los caribes de Canuco asistieron a las escopetadas y que el capitán Mayaracán decía a las Naciones: Vosotros matareis a los españoles; los Padres dejádmelos para mí. Aquellos Caribes de Canuco casi todos son fugitivos de nuestras misiones" (32).

Los frutos de la expedición capuchina, en términos misionales, son escasos. Sin embargo, su importancia no es poca en términos geográficos y políticos. Prácticamente son los primeros españoles

(31) Fray Félix de Villanueva: Carta al P. Jayme de Puxcerda sobre la expedición al Parime, 20 de junio de 1772. En J. STRICKLAND, Documents and Maps on The Boundary Question between Venezuela and British Guayana. Roma, ed. Unione Coop,. 1896, pág. 24.

(32) "Tomás de Mataró y Benito de la Garriga: Viaje por los ríos Caroní, Icabaru, Sierra de Pakaraima hasta las sabanas del rio Parime" (1772). En ARMEllada [29], pág. 133. 
en llegar al Mayarí, es decir a las sabanas del Uraricoera. En segundo lugar, vuelven con noticias recientes de los otros europeos que se acercan al Parime: los padres confirman la presencia de muchas armas de origen holandés entre los indígenas; $y$, cosa más peligrosa, los indígenas refirieron a los padres que «...los Portugueses estuvieron alli con pretexto de pasear y que a la despedida cogieron y se llevaron mucha gente, y que cuando nos iríamos tal vez haríamos los mismon (33). Como puede verse, no se trata ahora sólo de temores por la llegada de los portugueses; ellos están ya transitando por el Parime y falta poco para que se establezcan alli definitivamente.

Simultáneamente a la llegada de los misioneros a la misión de Auguri, se produce un levantamiento indígena en la región, tal vez provocado por la misma expedición de los capuchinos (34). Mayaracán, reunidos caribes y saparás, incursiona por los rios Chico y Caroní, atacando las misiones de Moroconí y liberando a los indígenas reducidos (35). El fraile Pedro de Fugarola es muerto y los indígenas de Grumapati y Barceloneta también se escapan, siguiendo Mayaracán hasta el alto Rupununi (36).

La reacción de Centurión a la noticia de la expedición capuchina fue muy violenta, también porque se estaba desarrollando al mismo tiempo su primera expedición por el Caura, acompañada por misioneros observantes. Es el mismo padre de la Garriga quien nos relata la reacción de Centurión:

Se puso bravo y demostró sentimiento el Comandante porque yo fui a la empresa; yo también (es que me llamó después de haber vuelto) y le di razón del motivo de mi viaje y ver los indios que por la concordia están bajo nuestro cuidado; y entonces parece daría satisfacción, diciéndome que, si iban los Padres Observante, era por el motivo de ir por el Caura: que pasaban por su territorio y por ser dificultoso introducirse por allá a la Parime, resolvió fuese el destacamento por la Paragua, y marchando por ahí no podían ir los Observantes sino los Padres catalanes por ser la Paragua de su territorio; y en esta

(33) Ibidem, pág. 131.

(34) El padre Cesareo de Armellada adelanta la hipótesis de que este levantamiento fue provocado por las torturas y maltratos a los indígenas por parte de un tal Antonio Reynal (ARMELlada [29], pág. 130).

(35) CivrieuX [11], pág. 976.

(36) P. Félix de Villanueva: Carta al Fray Jayme de Puxcerda 15 de septiembre de 1772. En Strickland [31], pág. 27; CivRIEux [11], pág. 976. 
suposición me pide religiosos para ir y le respondo que no puede ser hasta que vengan de España, y en eso quedamos (37).

\section{LA PRIMERa EXPEDICIón DE CeNTURIón AL PARIME (1772)}

En 1772 Centurión está listo para dar inicio a la realización de su plan, por largo tiempo preparado. Ya desde 1770 estaba en sus manos la aprobación de Solano: «Es muy de mi satisfacción el intento de penetrar a esa provincia, y reducir los innumerables indios gentiles que habitan sus selvas, conforme tengo comunicado a Vuestra Merced, y lo hago de propio puño: Celebrando el infatigable celo de Vuestra Merced, y la buena conducta con que procede en esta importante impresa" (38).

El 22 de mayo de 1772, después de dos años de pedidos y correspondencia, el Consejo de las Indias envía a Centurión la aprobación del Rey para la expedición a la laguna del Parime:

Por carta de Vuestra Merced del 28 de diciembre del año próximo pasado se ha enterado el Rey de los ofrecimientos que le ha hecho el indio capitanejo del paraje llamado la laguna Parime, que llegó a esa capital con el fin de conducir a los españoles al referido sitio, de modo que pueden posesionarse de aquellos terrenos y del cerro nombrado del Dorado; y han aprobado Su Majestad que fiado de la buena fe con que se ha presentado aquel capitanejo, haya Vuestra Merced procedido a la habilitación de la expedición que refiere ha salido ya al cargo del teniente de Artillería D. Nicolás Martínez, para lograr de este modo las ventajas que comprende llegar a ocuparse por nosotros algunos de aquellos parajes (39).

Nada más sabemos de este capitán indígena del Parime. Es probable que Centurión en una de sus cartas haya citado tal posibilidad o proposición indígena (aunque quedan dudas sobre la efectiva existencia de tal propuesta indigena).

El teniente de Artillería Nicolás Martínez salió de Angostura en enero de 1772, acompañado por dos padres franciscanos, un

(37) Benito de La Garriga: Carta al P. Comisario General de las misiones. 3 de noviembre de 1772. En CARROCERA [18], vol. II, pág. 178. La "concordia" a la cual se refiere es la división del territorio en 1734 entre las varias congregaciones misioneras presentes en el área RaMOs Pérez [16], págs. 515-516.

(38) Joseph Solano: Carta a Centurión, 3 de diciembre de 1770. AGNC, La Colonia, Papeles de Centurión, $\mathrm{n}^{\mathrm{Q}} 38, \mathrm{f} .122$.

(39) El Consejo de Indias a Centurión. Aranjuez, 22 de mayo de 1772. En GONZÁlEZ DEL CAMPO [6], págs. 379-380. 
sargento, un cabo, doce soldados, un cosmógrafo y dos intérpretes (40). La ruta contemplaba la navegación del Caura y, desde sus fuentes, pasar a las sabanas del Parime. Tal vez por la época del año en que se realizó la expedición (sequía) o por las dificultades del terreno, casi todos los expedicionarios estaban enfermos al llegar al alto Caura.

Desde el alto Caura se trasladan al cercano río Cuato, donde les «informaron que la mejor ruta para la Parime la ofrecía el río Paragua» (41). Martínez decide quedarse en el lugar para esperar la estación lluviosa, que tal vez les permitiría un paso más fácil por los ríos.

En mayo la expedición continúa su viaje hasta llegar al Paraguamusi, siguiendo luego hasta el río Anacapara, donde se encuentran con el subteniente Bernardo Lanzarote con los refuerzos enviados por Centurión tal vez llegados por el Paragua. Bloqueados por las crecidas de los ríos, deciden volver atrás, llegando a Barceloneta el 24 de septiembre (cfr. mapa anexo 2).

\section{Segunda EXPEdición dE CENTURión (1773)}

Centurión no abandona su proyecto y el 17 de marzo de 1773 otra expedición sale de Angostura. Esta vez se trata de algo mejor organizado: 125 hombres en armas, más indígenas, al mando del Teniente de Infantería don Vicente Díez de la Fuente. La ruta, esta vez, será la del Paragua.

En el alto Paragua la expedición organiza su primer campamento fijo en la confluencia con el río Paraguamusi. Después de cinco meses en este sitio, que se convertiría más tarde en la "ciudad" de Guirior, en homenaje al virrey de Santa Fe (cfr. mapa anexo 2), Díez de la Fuente envía al cabo Isidoro Rendón, intérprete de la lengua caribe, con un grupo de soldados e indígenas a la descubierta del Parime.

La expedición bajó por el río Uanamara (brazo del río Uraricoera) y continuó por el Uraricoera, hasta la confluencia con el Tacutú: «navegó hasta la boca del Río Mao, escribe Centurión, por donde se introdujo a el de Abarauru, remontando por ellos hasta aproximarse a la laguna Parime, de donde retrocedió y

(40) Instrucción de Centurión a Martínez. AGS. Guerra Moderna, 7166.

(41) OJER [2], pág. CLXXII. 
volvió a salir por la boca del Mao, y desde allí hasta la de Curaricara" (42).

Intentemos aclarar el recorrido de Rendón utilizando los nombres modernos de los ríos: después de llegar a la confluencia Uraricoera-Tacutú, el grupo navega el río Tacutú hasta la confluencia con el río Maú. Desde aquí no siguen por éste, sino que continúan por el Tacutú que en su parte alta es llamado por los makuxís Auaraurú. De retorno, y sin considerar la entrada al río Surumú por la derecha, regresan a la llamada "boca del Mao», o sea a la confluencia Uraricoera-Tacutú.y de aquí hasta el Curaricara (probablemente el Mayarí) (cfr. mapa anexo 2).

Es interesante notar el uso del término "aproximarse" al Parime, que Centurión utiliza. De hecho, al «espacio mítico», donde la laguna del Dorado se encuentra, es posible sólo "aproximarse», nunca llegar. En su lugar Rendón encuentra sólo sabanas inundables y debe aceptar la realidad: la laguna es sólo un sueño.

Las fuentes españolas - sobre todo las cartas de Díez de la Fuente y de Centurión- no señalan ningún choque con los indígenas, por el contrario todas se esfuerzan por demostrar que el grupo de Rendón fue bien aceptado por los indígenas locales, sobre todo makuxís. Bien diferentes son los «datos"que reportan las fuentes luso-brasileñas. Por ejemplo, en una carta de Joïo Pereira Caldas a Martinho de Mello e Castro del 28 de febrero del 1776, se hace referencia a varios ataques de los indígenas paravianas (paravillanas) y caripunas (probablemente caribes) contra la expedición española (43).

Volviendo a las fuentes españolas, parece que Rendón consiguió aliarse con algunos grupos locales de makuxís y los convenció a "aldearse». Funda así tres pueblos: San Juan Bautista de Cada Cada; Santa Bárbara y Santa Rosa de Curaricara, «en las orillas del Parime» (44).

Santa Rosa de Curaricara fue fundada en la confluencia del río Curaricara con el Parime (Uraricoera) (cfr. mapa "Flores», anexo 3). El río Curaricara, según Lobo de Almada es el río Uraricapara (45). Con esta aclaración, sin embargo, no avanzamos 7412.

(42) Manuel Centurión: Carta a Gálvez 27 de julio de 1776. AGS, Estado,

(43) "João Pereira Caldas: Carta a Martinho de Mello e Castro" (28 de febrero de 1776). En VV. AA. [17], vol. I, págs. 134 y ss.

(44) Manuel Centurión: Carta a Gálvez (1777). En M. C. Cal Martínfz, La defensa de la integridad territorial de Guayana en tiempos de Carlos III. Caracas, ed. Academia Nacional de la Historia, 1979, pág. 355.

(45) Manuel G. LOBo DE Almada, "Descriçao relativa ao Río Branco e seu Territorio" (1787). En Revista Trimestral do Instituto Historico Geográphico do Brasil, vol. XXIV, Río de Janeiro, 1861., pág. 635. 
mucho. Dejando a ulteriores investigaciones el análisis de estos nombres, nos parece que este río puede ser el Mayarí. De hecho, los mapas "Flores» y de Surville, permiten esta hipótesis, teniendo presente la distorsión geográfica provocada por la ausencia en la representación cartográfica del río Surumú/Cotinga, intermedio entre el Tacutú y el Mayarí (cfr. mapa anexo 2).

El segundo pueblo, Santa Bárbara, fue fundado en posición intermedia entre la confluencia Mayari-Uraricoera y la de Uraricoera con el Tacutú. Finalmente, San Juan Bautista de Cada Cada fue fundado cerca de la confluencia del Uraricoera con el Tacutú (que los españoles conocían como Maú). En el mapa "Flores» (anexo 3) se indica la localización de los tres pueblos.

Realizada su misión, Rendón regresa al Paraguamusi con el fin de reunirse con Díez de la Fuente. Centurión relata de la siguiente manera esta vuelta:

Que dejando el dicho Intérprete para custodia de ellos al Sargento Marcos Zapata con 14 hombres se retiró luego a las Cabeceras de la Paraua donde el Oficial Comandante estaba ya fundando la ciudad de Guirior, y en tan dilatada y prolija exploración no vieron aquellos españoles ningunos Portugueses, ni aun vestigios de establecimiento alguno de ellos: manifestando la quietud conque vivían los Indios en aquellas Selva, y Márgenes, y las noticias que se tienen, de los Dominios de Su Majestad Fidelísima estaban muy distantes, y que sus vasallos no habían intentado nunca, penetrar ni poblar aquellos desiertos (46).

En los pocos meses de ausencia de Rendón, Díez de la Fuente ha adelantado la construcción de Guirior. En octubre de 1774, un año después de la llegada de la expedición, «la ciudad» tiene un castillo, un cuartel, seis o siete ranchos, habitados por blancos y negros, y 16 ranchos de indios. «El número de gente que compone y ocupa dicha población de Guirior consiste en 20 almas de comunión. Esto es, entre soldados, vecinos, y vecinas, y los indios son 120 almas; el número de negros entre hombres y mujeres, de 26 personas» (47).

La descripción que acabamos de citar es del padre Félix de Vich, que junto con el padre Buenaventura, el cabo Juan Antonio Cuello y tres negros, habían salido de Barceloneta por orden del Padre Prefecto y del Gobernador Centurión, para juntarse a la

(46) "Manuel Centurión: Carta a Gálvez" (1776). En CAL [44], pág. 355.

(47) "P. Félix de Vich: Relato del viaje por el rio Paragua arriba, hasta las cabeceras del Paraguamusi y ciudad de Guirior 7 de noviembre de 1774. En CARrocera [18], vol. II, pág. 260. 
expedición al Parime (10 de agosto de 1774). El viaje fue muy pesado para los dos padres y uno de ellos, el padre Buenaventura enfermó de «calenturas" y terminó falleciendo una vez llegados a Guirior. Frente a estos eventos, el padre Félix decide no continuar el viaje (48). Termina así la participación misionera española en la conquista del Parime. El padre Félix cita, en su relación, la huida de los indigenas aldeados por los españoles en el Parime, de la cual sin embargo no hablan los textos de Centurión. De hecho, las noticias que el padre Félix refiere en su descripción de la situación de Guirior nos dan una imagen poco pacífica de la permanencia de Zapata con los makuxís. Parece que

todas aquellas naciones de indios, que son muchas naciones, habían hecho paces entre sí y se habían unido para ir contra los españoles, con quienes han tenido ya tres choques. Y uno de los que se hallaron en uno de los choques, me dijo que había ya más de mil indios con armas de fuego y mataron al práctico llamado Paramacari y otro compañero. Según otra noticia que tengo, miro muy lejos de poblarse el Parime y laguna (49).

En todo caso, tales noticias tienen que ser utilizadas con mucha atención. Se trata sin duda de eventos narrados al padre y no vistos por él de hecho, Díez de la Fuente no cita estas rebeliones y que pudieron ser exageradas con facilidad. Además, por lo que sucederá después de la tercera expedición, podemos afirmar que, por lo menos, algunos grupos de makuxís se mantuvieron aliados a los españoles.

Señalados estos problemas de interpretación de los datos, se puede afirmar que la situación general no era tranquila. Parece que la región estaba ya "saturada" de noticias sobre los europeos y su llegada: holandeses al noroeste; portugueses al sur y españoles desde el oeste. La tensión en la región se hace bastante explícita: está "todo alborotado", son las palabras de Díez de la Fuente, reportadas por el padre Félix de Villanueva, en una carta al padre Jayme de Puxcerda, donde relata una revuelta indígena en el Caroní Chico:

Los Indios del monte han quemado un pueblo que había hecho D. Vicente para ir a la Parima en el Caroní Xiquito, muertos, y heridos sus vecinos, y Centurión desesperado ha

(48) Ibídem pág. 261.

(49) Ibídem, págs. 261-262. 
mandado todos los hombres de Upata (menos 16 inválidos) forzados ir en seguimiento de los matadores y si van, todos los dan por perdidos, porque aquellos Indios están cargados de armas de fuego, y se discurre revuelto con holandeses. D. Vicente mucho ha escrito desde Paruamuxi, que estaba aquello todo alborotado, y estaba circuido de enemigos y pedía mucho socorro; otros dicen que ya están todos muertos: en fin, todos dicen que no saldrá Centurión con la suya de ir a la Parima (50).

\section{TERCERA EXPEDICIÓN DE CENTURIÓN (1775)}

Pasan casi dos años antes que Centurión se decida a organizar otra expedición al Parime. Las razones de esta demora, conociendo los planes de Centurión, no están muy claras. Es cierto que los españoles, de cierta manera, habían ya conquistado esas regiones: el sargento Zapata, con unos españoles e indígenas del Orinoco, estaban viviendo en los tres pueblos del Parima, reduciendo a los indígenas makuxís y «vapidianas" (51). Durante esta permanencia, el único europeo que Zapata encontró fue el cabo de un "puesto" holandés quien, fingiéndose desertor, visitó el pueblo español de San Juan Bautista de Cada Cada y volvió después a referir a los holandeses del Esequibo las andanzas de los españoles - tal vez, sea éste el Gervais Lecler que encontraremos más adelante-

Sin embargo, esta conquista es precaria, ya que no están bien establecidos los pueblos intermedios entre el Orinoco y el Parime, que deberían funcionar como «escalas» para comunicarse con las recién fundadas aldeas. Así, estos dos años pasan organizando el fortalecimiento de la conquista ya realizada, sin conseguir grandes logros a causa de las continuas rebeliones indígenas.

Antes de describir la última expedición de Centurión al Parime, vale la pena calcular la distancia entre el Orinoco y el Parime, desde el punto de vista de una expedición realizada en esos días. Para esto, utilizaremos un cálculo reportado por el brasileño Joaquím Nabuco en su «Memoria primera" para la disputa territorial Brasil-Gran Bretaña. Nabuco calculaba el recorrido basándose en declaraciones hechas por los españoles capturados por los portugueses:

D'après les Espagnols trouvés sur le Río Branco, il fallait calculer comme suit les distances d'Angostura à S. Joïo Baptista:

(50) Fray Félix de Villanueva: Carta a Jayme de Puxcerda, sobre el levantamiento de los indígenas en las orillas del Paragua, (18 de mayo de 1774). En STRICKLAND [31], pág. 30.

(51) Se trata de indigenas Wapixana. La referencia se encuentra en una Carta de Díez de la Fuente a Centurión del 3 Julio de 1776. Cfr. Cal Martínez [44], pág. 359. 
«d'Angostura à Barceloneta, sur le Paraua, 3 jours par terre; de barceloneta à $\mathrm{S}$. Jozè, 18 jours par eau; de $\mathrm{S}$. Jozè a $\mathrm{S}$. Vicente, 16 jours par eau; de S. Vicente, en remontant par le Paravamussi jusq'aux monts Pacaraima, 2 jours; pour frangir les montagnes, un jour, on entre alors dans l'Aracuque, où il ne faut plus qu'un quart d'heure pour arriver jusqu'ao Parima ou Rio Branco des Pougais; de cet endoit à Santa Roza, 2 jours en descendant le courant; de Santa Roza à S. Joïo Baptista, 6 jours en descentant la rivière" (52).

Así, según este cálculo, desde Angostura hasta S. Juan Bautista de Cada Cada, se empleaban 53 días. Otro cálculo del Capitán Sturm (que comandó la contraofensiva portuguesa) llega a tres meses y tres días, pero considerando una expedición cargada con pertrechos militares (por ejemplo, la artillería) (53).

En octubre de 1775, Centurión encarga a Díez de la Fuente la organización de una nueva expedición al Parime. Este confía el mando de la misma al Cadete de Infantería Don Antonio López. Acompaña también esta expedición el «intérprete de caribes» Isidoro Rendón que había participado en el viaje anterior al Parime. Con ellos van dos españoles treinta indígenas y un «minero" para intentar descubrir yacimientos de oro. Contrariamente a lo que piensa González del Campo (54), quien interpreta la presencia de este "minero" como una prueba de la creencia todavía viva del Dorado, la participación de este personaje demuestra que la búsqueda del oro se estaba realizando de manera diferente: búsqueda de minas, análisis de los terrenos, etc.

Salidos de Guirior el 27 de septiembre, relata Díez de la Fuentes, "no tuvieron otro contratiempo que un choque corto con unos caribes, los cuales no ofendieron a ninguno de nuestra gente, pero si el Cabo Andrés Salazar de un pedrerazo mató dos, o tres de ellos, y huyeron los otros" (55).

A llegar a los pueblos españoles del Parime, se encuentran con una situación tranquila y buenas relaciones entre españoles e indígenas makuxís y wapixanas. Alcanzado el pueblo de San Juan de Cada Cada, conducidos por un makuxí se marchan a

(52) Joaquín Nabuco, Le Droit du Bresil: Premier Memoire. Paris, ed. Laburs, 1903 , pág. 174.

(53) Ibidem, pág. 177.

(54) GonZález del Campo [6], pág. 114 (nota 34).

(55) "Díez de la Fuente: Carta a Centurión" (3 de julio de 1776). AGS, Estado, 7412 . 
visitar un cerro llamado Apucuano, donde piensan encontrar oro, situado a 10 días de navegación por el Tacutú arriba:

Seis capitanejos de nación Macusis (que son los más inmediatos a dicho Cerro) se amistaron muy bien con nuestros españoles, de suerte que ni aun escrúpulo tenían de comer sus comidas, y de acostarse con ellos en sus chinchorros, tres días que dice estuvieron aí; y aun pretendía un Capitanejo Macusi llamado Mayarabay poner su pueblo en la cima del Cerro luego que volvieran los españoles. El expresado Cerro dice que lo alto es de sabana, y las faldas de Sabana y monte (56).

Una vez llegados al Cerro, subieron Rendón y López acompañados por el minero y varios indígenas, guiados por una makuxí de nombre Rosa (a quien volveremos a encontrar más adelante). Sería interesante descubrir a cuál monte se están refiriendo. El único monte con "sabanas arriba" es el Roraima, aunque parece imposible que hayan llegado tan al norte. De cualquier manera, la búsqueda de mítico Parime está coherente con la del monte dorado (la "Montaña de cristal" del holandés Gravesande), ya que la "salida al monte" tiene su lugar importante en los viajes iniciáticos de la Edad Media y, particularmente, para los alquimistas de los siglos XVII y XVIII. Por otro lado, no deja de ser interesante el hecho de que también para los makuxís la tal montaña participa del orden de la realidad mítica y no de la empírica: El nombre «apucuano" parece una deformación del término makuxí apocoino:, gran palo central de la casa indígena, que representa un árbol mítico que liga la tierra con el cielo. Por otro lado, el monte Roraima es para los makuxí el gran "árbol» cortado por dos héroes míticos.

Durante la expedición al Cerro seis españoles desertan, por maltrato recibido del cadete. Son éstos los primeros en encontrar a los portugueses, y quienes delatarán la presencia de la expedición española al río Tacutú.

Dejemos por ahora la expedición española en búsqueda del "cerro dorado" y volvemos a Guirior para completar el cuadro de la situación general de la región en vísperas del «incidente» bélico-diplomático con los portugueses. Ocho meses han pasado desde la marcha de la expedición de Rendón y López. La región está intranquila y, además, ante la ausencia de noticias del Pari-

(56) Idem. 
me, se teme lo peor. Una negra relata que la mitad de la expedición había muerto antes de llegar a la laguna, a causa de los asaltos indígenas (57):

para tumbar un moriche habian de poner centinelas, porque á los golpes de la hacha ya salían los Indios del Monte, y que mas arriba ya no se atrevían á tumbar, y que cerca de la laguna los dejó en un grande combate, con muchos Indios de Monte; y como ellos estaban medio muertos de hambre, y tal vez sin municiones se juzga que los acabarían y cuando no los Indios; los holandeses (58).

Como puede verse, los temores se extienden cada vez más, atribuyendo la posibilidad del fracaso de la expedición o a los indígenas "del Monte" o a los holandeses. Nadie todavía piensa en los portugueses. Al mismo tiempo, llega a Guirior un soldado de Santa Rosa sobreviviente de un levantamiento indígena:

En Santa Rosa, relata el padre Vich, los mesmos Indios del Pueblo mataron al Cabo, y dos soldados y al otro le abrieron la cabeza con un golpe de hacha, y no se si ellos lo dejarían por muerto; ó si se escapó, y al cabo de un mes llegó á Guirior con la cabeza muy hinchada, y con muchos gusanos ya grandes que causaba lastima y compasión, este dio noticia de lo sucedido en Santa Rosa; y dijo que en el varadero había encontrado muerte al pobre Oroño que iba á mudar á uno de los soldados. Dios los aya perdonado (59).

En Guirior la situación empeora cada día más. Los habitantes "no se atreven a salir a pescar, ni cazar, ni á lavar ropa al río", por miedo a los indígenas levantados. Finalmente, entre abril y mayo, el levantamiento se da de verdad, con varios muertos en ambas partes. El año siguiente se intentó culpar a los capuchinos de los hechos ocurridos en Guirior, mientras que éstos sostenían que las causas de la rebelión se debían al maltrato sufrido por los indígenas por parte de los españoles civiles y militares (60).

(57) STRICKLAND [31], pág. 31 pág. 31 .

(58) Carta del P. Félix de Vich: 16 de mayo de 1776. En Strickland [31],

(59) Idem.

(60) Fray Félix de Villanueva: Declaración de un vecino sobre el levantamiento de Guirior, 12 de julio de 1777. En STRICKLAND [31], pág. 32. 


\section{EL CONFLICTO HISPANO-PORTUGUÉS EN EL RÍO BRANCO}

La llegada al río Negro del holandés (o francés) Gervais Lecler, precipita los acontecimientos. Lecler, que desde el Esequibo había bajado por el río Branco y probablemente visitado los nuevos pueblos españoles, comunica la presencia de los españoles en la confluencia Uraricoera/Tacutú y sus intentos de reducir a los indígenas Makuxís de la región (61). Además, parece que inmediatamente después de Lecler se registró la llegada de un desertor español -desde San Carlos, según las fuentes lusitanas; desde el Parime según Centurión- que confirma el relato del holandés (62).

Lecler había llegado a Barcelos, capital de la Capitanía de San José del río Negro, el 16 de marzo de 1775 con la noticia de la presencia española en el río Branco. Inmediatamente, estando esta Capitanía subordinada a la del Gran Pará, el gobernador Tinoco Valente envía la noticia a Belém y de donde salen 50 hombres armados para expulsar a los «invasores». El 3 de octubre de 1775, con otro centenar de hombres, la expedición sale de Barcelos por el río Branco, en dirección al río Uraricoera (63). Tinoco Valente describe la decisión de enviar esta expedición de la siguiente manera:

Tomando eu as referidas noticias na mais séria consideraçao com que devo olhar para um negocio, que nada menos envolve, que a segurança, e conservaçao dos reaes dominios de El-Rei meu senhor; me propuz como governador seu, neste continente a expedir uma pequeña tropa que fizesse desalojar e prisionar os ditos intempestivamente estabelecidos, e fortificados naquelle sitio, ou outro qualquer dos mesmos reaes dominios do meu fidelissimo soberano (64).

(61) Tinoco Valente: Carta a Centurión, 13 de octubre de 1776. En LoBo DE Almada [45], pág. 649.

(62) Nabuco [52], pág. 167.

(63) A. AdOnias, A Cartografia da Regiao Amazónia. Rio de Janeiro, 1963, vol. II, pág. 148. Asimismo Tb. F. X. RIBEIRo DE SAMPAIO, "Relaçao geographica-historica do Rio Branco da America Portuguesa" (1777). En Nova DA CosTa, $O$ Vale do Rio Branco. Rio de Janeiro, 1949, pág. 191. Las fuentes españolas dan cifras un poco diferentes. Centurión, escribiendo a Gálvez, refiere que el gobernador del Pará envió a Tinoco "...en brevísimo tiempo... un refuerzo de 200 hombres de tropa y quinientos indios fusileros con el cual sorprendieron al destacamento de un sargento y 12 soldados que teníamos en Cada-Cada para custodia de los citados pueblos del Parime". En Manuel Centurión: Carta a Gálvez, 27 de julio de 1776. AGS, Estado, 7142.

(64) Tinoco Valente: Respuesta a Centurión, 13 de octubre de 1776. En LoBo DE Almada [45], pág. 649. 
El comandante de la expedición portuguesa es el ingeniero técnico capitán Felipe Sturm, con amplia experiencia en el Amazonas (65). Los portugueses remontan el río Branco y sorprenden al teniente Cuello con doce soldados españoles en San Juan de Cada Cada (66). Algunos españoles e indígenas consiguen escaparse al pueblo de Santa Rosa, los demás son capturados. Sin embargo, los portugueses persiguen a los fugitivos hasta Santa Rosa (12 días de viaje), donde consiguen capturar otros cuatro españoles (67).

Por los prisioneros, los portugueses se enteraron de la presencia del cadete español quien, con 27 soldados y 30 indígenas, está buscando el «monte dorado" (Maú arriba) o minas de oro, con 9 embarcaciones armadas de 4 pequeños cañones. Sturm envía 25 soldados en 4 piraguas, armados con dos piezas de artillería, a la búsqueda de estos españoles (68). Sin embargo, no consiguen encontrarlos y, así, vuelven a la base establecida en la confluencia del Uraricoera con el Tacutú. Esperando la vuelta de los españoles, los portugueses sorprenden a los desertores españoles que ya citamos en el párrafo anterior. Como escribe Tinoco:

Com aquella remessa foi participado pelo commandante da dita tropa, que pelo río Tacutú, tinha entrado um cadete acompanhado de vinte a sete soldados, indios praticos, e bastantes petrechos de guerra, a descobrir um serro, ou lago dourado, que estavam situados entre o gentio Caripuna, quatro dias de viagem acima da sua bocca, cuja informaçio Ihe tinham dado os mesmos prisionados: interpoladamente se seguiram a esta conta seis soldados desertados do dito cadete, e logo depos mais um que fizeram sete, que sendo tambem remetidos á minha presença, contestaram a sobredita noticia, e seguiran estes a mesma viagem que os primeiros (69).

De esta manera, con informaciones más exactas, los portugueses consiguieron sin mucha lucha capturar al resto de los españoles a su vuelta, en la confluencia del Uraricoera con el Tacutú.. Después de la captura, y mientras son llevados prisioneros, algunos indígenas amigos de los españoles consiguen esca-

(65) AdONIAs [63], pág. 149.

(66) "Díez de la Fuente: Carta a Centurión" (3 de julio de 1776). AGS, Estado, 7412.

(67) Idem.

(68) Idem.

(69) Tinoco Valente: Respuesta a Centurión 13 de octubre de 1776. En LoBo DE Almada [45], pág. 650. 
parse y, después de una larga y penosa marcha llegan a Guirior. Son éstos los que relatan los acontecimientos a Díez de la Fuente quien, a su vez, envía una carta a Centurión informándole del conflicto con los portugueses:

El día 20 del próximo pasado Junio llegó a este Puerto el Capitán Arimucaype, acompañado de doce Almas de su Nación, seis hombres, cuatro mujeres, y dos muchachos, de los que habían marchado de este pueblo con la expresa expedición, sin carta, ni licencia alguna y aun hasta sin ropa ni chinchorro, quien haciéndole cargo como venía sin licencia, y de la suerte dicha y sin compania de tropa, respondió que él venía huido de los portugueses, quienes aprisionaron al Cadete y su escolta en la boca del Río Mao, y a ellos y sus compañeros juntamente y que a los españoles los embarcaron al instante con Guardias en Piraguas, y con grillos, excepto el Cadete, y los condujeron a una población grande que tienen inmediata al Río Parime abajado, y que a ellos los dejaron en dicho Puerto aprisionados con cadenas para que trabajaran cargando tierra en conchas de tortuga a una casa grande con piedra que están haciendo para poner cañones más grandes que los nuestros. Infiero serán de a cuatro según él pinta: Que hay muchos portugueses y mujeres también blancas de ellos y mulatas, y que esta prisión acaeció a la retirada del Cerro Apucuano ya para caer al Parime, donde desemboca dicho Río Mao (70).

Diez de la Fuente no confía mucho en los indígenas y los interroga largamente. Una de las preguntas se refiere a cómo consiguieron escaparse. Así, se entera que, a parte de los fugitivos de los pueblos, algunos de los indígenas fueron liberados por los mismos portugueses después de recibir una carta de Barcelos, donde presumiblemente, así les ordenaban. Rendón, ya prisionero de los portugueses, se aprovecha de esta inesperada posibilidad para encomendar a los indígenas (se trata de la misma india makuxí Rosa que los había conducido al cerro Apucuano) de informar a los españoles de Guirior de lo sucedido.

Añade más esta india, y el capitán: preguntándoles cómo habían podido escapar estando aprisionados, y dicen que a los diez días llegó una carta de abajo, y al instante que la leió el comandante, que es un teniente, los puso en libertad, y ellos con este motivo y el de haberles dicho Rendón antes que les 7412 .

(70) Díez de la Fuente: Carta a Centurión 3 de Julio de 1776. AGS, Estado, 
despacharan luego que tengan ocasión vayanse a Paraguamusi, y cuenten todo lo sucedido al Comandante, y diganle también que Yo, si tengo ocasión me huiré con los españoles, y por la mar saldré a la Angostura (71).

El comandante de Guirior descubre también que una parte de los fugitivos indígenas no regresaron con el grupo makuxí al Paraguamusi. Por ejemplo, los kipurocotos" y los paravillanas" que habian sido reducidos en los tres pueblos del Uraricoera, se habían ido cimarrones, es decir al monte (72). Así, después de casi un año de la salida de la expedición portuguesa de Barcelos, los españoles son expulsados (la mayoría prisioneros en Barcelos y en Belém) y los portugueses pueden proceder a la ocupación del territorio. Ahora existen ya las condiciones y la necesidad -se teme la respuesta española- para cumplir con la orden real de 1762 de construir un fuerte en el río Branco.

\section{LA CONTRAOFENSIVA ESPAÑOLA Y EL TRATADO DE SAN ILDEFONSO (1777)}

Después del conflicto en el río Branco, Centurión no abandona la idea de contraatacar. Envía el capitán de infantería Barreto a Barcelos con cartas de protesta y la misión de conseguir la liberación de los prisioneros. Por toda la segunda mitad de 1776, los dos comandantes intercambian protestas, cada uno aportando sus razones y pretendiendo tener derecho a las tierras del río Branco. Centurión está dispuesto a aceptar una parte de la conquista portuguesa, pero pretende que se fijen los límites en la confluencia Uraricoera/Tacutú (73).

En sus respuestas Tinoco Valente intenta demostrar, a su vez, la antigüedad de la presencia portuguesa en el río Branco, asumiendo las "entradas» de particulares en búsqueda de esclavos indígenas como expediciones oficiales $\mathrm{y}$, por esto, como legítimos descubridores en nombre del Estado lusitano:

sendo certo obtel-a [esa tierra] El-Rei meu senhor ha mais de cincoenta e dous annos, o que bem mostrarei por documentos judiciaes, e certificarei nio só com as pessoas fidedignas que
(71) Idem
(72) Idem
(73) Cal Martínez [44], págs. 53-54. 
passaram aquelles rios debaixo das bandeíras reaes de Portugal nos annos de 1725, 1736, 1740 e 1744, como foram o capitao Francisco Xavier Mendes de Moraes, o capitao Belchior Mendes, Christovao Alvares Botelho, o capitao Francisco Xavier de Andrade, Lorenço Belforte, Joseph Miguel Ayres, Sebastiao Valente, Frei Jeronymo Coelho religioso carmelita, o indio Paulo, o Principal Theodozio Joseph, o capitao Francisco Ferreira, Domingos Lopes, Francisco Rodrigues, Manoel Pires, 0 principal Ajurabá, o sargento-mor Miguel Indio, o abalizado Arubaiana, o principal Faustino Cabral, o principal Camandri, o principal Ascanio, que todos, e outros muitos subiram pelas campinas dos referidos limites mais de mez de viagem, até se lhe acabarem, sem que encontrassen os srs. hespanhóes, ou tivessem noticia de que por aquelles districtos passassem em tempo algum, e menos outra qualquer naçïo, sendo os referidos os primeiros que facilitaram, e descobriram aquella navegaçio, ne que bem se justifica a legitima posse que ampliaram ao seu fidelissimo soberano (74).

Percibiendo la fragilidad de esta defensa, los portugueses en los años sucesivos intentaron demostrar que los portugueses habían construido ya antes de la llegada de los españoles un establecimiento pesquero en el río Branco - en realidad mucho más abajo del Uraricoera y con carácter estacional- y que, además, las entradas españolas no eran diferentes de las lusitanas (captura de esclavos). Ribeiro de Sampaio, particularmente, demostraba estar consciente de la diferencia entre las entradas y la fundación de pueblos para reclamar derechos de ocupación. Por esto, no duda en negar la fundación de los tres pueblos españoles en el Uraricoera, reconociendo la existencia de sólo uno (Santa Rosa), pero como campo militar provisional. En un país de ríos, afirma Sampaio (1777), «las mismas embarcaciones de transporte constituyen la fábrica (usine), el almacén y la fortaleza» (75).

Del lado de los españoles los acontecimientos parecen trabajar en favor de los portugueses. Centurión, también en consecuencia de su polémica con los capuchinos, regresa a España en 1777, y es sustituido por el gobernador interino D. José Linares quien es del parecer que los portugueses pretenden «fundar en antiguos hechos que carecen de veracidad un imaginario derecho del Rey su Amo" (76).

Auxiliado por el ingeniero militar Agustín Crame, autor de un

(74) Tinoco Valente: Respuesta a Centurión 13 de octubre de 1776. LoBo DE Almada [45], pág. 652.

(75) En NaBuco [52], pág. 181.

(76) José Linares: Carta a Gálvez, 24 de enero de 1777. AGI, Caracas, 445. 
"Plan de defensa para la provincia de Guayana», Linares organiza la contraofensiva (77). Los objetivos serán los establecimientos portugueses en el alto río Negro y, naturalmente, los nuevos en el río Branco. En realidad, el plan de Crame era aun más ambicioso: intentar la conquista del Amazonas, hasta su desembocadura. Este plan respondía, desde el norte, a una estrategia española no oficial (la de Ricla) de conquistar todo el Brasil aprovechando «la oportunidad de la guerra de Inglaterra con sus Colonias para dejar fuera del cuadro a Portugal, haciendo en América del Sur con los lusitanos lo que en América del Norte habian hecho los ingleses eliminando el dominio francés" (78).

Linares ordena a D. Antonio Barreto que organice el ataque desde el alto Orinoco. Sin embargo, pocos meses después, enterado de la cantidad de tropas de que disponen los portugueses, Linares le recomienda prudencia, ordenándole quedarse inactivo en San Carlos (79). Con todo, el proyecto de contraofensiva se mantiene en pie, hasta que no interviene directamente el Rey español para cambiar completamente los planes.

Resumimos lo dicho hasta ahora, citando parte de un informe del capuchino La Garriga:

En otra ocasión escribí a V.P.M.R. que en la Parime los portugueses del Río Negro y Amazonas del gran Pará cogieron a un destacamento de soldados españoles que de Guirior bajaron a la Parime y boca del río Mao en descubrimiento del Dorado de Centurión, y que después el Comandante interino de Guayana D. José Linares envio una expedición al alto Orinoco y Río Negro para vengar el atentado de los portugueses, pero no obró cosa, por ser poca tropa y estar bien guarnecidos los contrarios; pero después el Sr. Intendente de Caracas, por orden del rey, previno enviar cerca de $\mathbf{3 0 0}$ hombres más para el mismo fin de represalias y me escribió este caballero encargándome la provisión de víveres de carne, casabe, puesto todo en Barceloneta, curiaras, indios, bestias de silla y de carga necesarios; y así que ya que dichos hombres se embarcaban en la La Guaira para venir, me avisó el mismo Intendente que suspendiese las expresadas providencias, porque llegó en aquel instante orden contraria del rey y me dio las gracias de parte suya y de Su Majestad por nuestro desempeño del real servicio (80).

(77) Cal Martínez [44], pág. 80.

(78) Ibidem pág. 97.

(79) José Linares: Carta a Antonio Barreto, 1777. AGI, Caracas, 445.

(80) P. Benito de La Garriga: Informe sobre la situación de la Misión de Guayana, 1 de febrero de 1779. En CarRocera [18], vol. II, pág. 339. 
Veamos lo que había sucedido en Europa. Con la salida al trono portugués de Maria I, Pombal había sido alejado del poder y lo mismo había sucedido en España con Grimaldi, substituido por Jose Moñino conde de Floridablanca (81). De esta manera, las relaciones entre las dos potencias ibéricas había mejorado substancialmente y se habian tomado acuerdos para discutir un nuevo tratado de límites para los territorios americanos. Ya a finales de 1776, en España, se había formado una junta a la cual el marqués de Valdelirios -ex-comisionario de límites en 1750 en el Rio de La Plata - había remitido toda la correspondencia de Centurión y el informe de Vicente Doz (enero 1777) sobre los acontecimientos del Parime (82).

No se piense que España ceda con facilidad sus derechos. Aún cuando exista la voluntad de trasladar a la mesa de las negociaciones el conflicto fronterizo, España no se queda esperando. De hecho, casi como respuesta a los acontecimientos del Parime, se envía desde España una expedición militar al mando de Pedro Cevallos quien conquista Santa Catalina (sur de Brasil) el 5 de marzo de 1777 y, poco, después, la Colonia de Sacramento, que los portugueses ocupaban por no haberse ratificado el Tratado de Madrid de 1750.

El primero de octubre de 1777 se firma en San Ildefonso los preliminares del nuevo tratado de límites entre España y Portugal. Por este tratado España recupera el territorio de las siete misiones del Paraguay y otros territorios al sur de Brasil, mientras que Portugal, consolida espacios en el sur y consigue el mantenimiento de los establecimientos en el río Amazonas (recordemos que éste era español por derecho descendiente del Tratado de Tordesillas).

Por lo que se refiere a nuestra región, el acuerdo reproduce el del Art. 3 del Tratado de Madrid, aunque reducido y parcialmente ambiguo (art. XII):

as pessoas que se nomearem para execuçao d' este Tratado assignalarao aquelles limites, buscando as lagoas e ríos que se juntem ao Japurá e Negro, e se avisinhem mais ao rumo do Norte, e n'ellas fixarao o ponto de que nao deverá passar a navegaçao e uso de uma nem de outra Naçao, quando apartando-se dos rios haja de continuar a fronteira pelos montes

(81) J. C. MACEdo de SoARes, Fronteiras do Brasil no Regime Colonial Rio de Janero, 1939, pág. 167.

(82) Cal Martínez [44], pág. 115. 
que medeiam entre o Orinoco e Maranhao ou Amazonas, endireitando tambem a linha da raia, quando podér ser, para a aparte do Norte, sem reparar no pouco mais ou menos de terreno que fique a uma ou á outra Coróa, comtanto que se logrem os fins já explicados, até concluir a dita linha onde findam os dominios das duas Monarchias (83).

Una tal formulación sólo podía crear confusión. En verdad, un poco más claras eran las ideas de los españoles integrantes de la Junta. Para éstos, kentrando por el río Parime y Tacotá hasta el punto en que permitiesen navegarlo sus aguas, se observase en él su latitud, y longitud, y se tirase una linea recta del Este por el aire que fuese a terminar en el mar océano en igual altura del Polo" (84). Estas indicaciones dadas por la Junta a Gálvez reproducen, mas o menos, la hipótesis de Centurión, cuando proponía a Tinoco Valente que la frontera pasase por la confluencia Uraricoera/Tacutú.

Sin embargo, los portugueses consiguen imponer su versión, basada sobre el artículo 5 del Tratado de 1750 (donde se cita la cordillera, por ese tiempo imaginaria, que divide las cuencas del Orinoco y del Amazonas). Parece un poco raro que los españoles, después de todo el alboroto suscitado a raíz del conflicto en el Parime, no hayan intentado mantener la hipótesis de Centurión. En verdad, un intento fue avanzado ya en la discusión de los preliminares del Tratado. En el borrador español del «plan del Tratado" era previsto un artículo que pedía la restitución de los tres pueblos españoles en el Parime:

Se restituirán al estado que tenía en fin de septiembre de 1775 las Poblaciones Españolas de Indios establecidas en el río Parime llamadas San Juan Bautista de Cada Cada no distante de la boca del río Mao. La de Sta Bárbara un poco más arriba o al norte, y la de Sta. Rosa de Curaricara cerca de la unión del río de este nombre con el Parime, restituyendo también los Indios cautivados en ellas, el Sargento y soldados; el Cadete D. Antonio López, y su comitiva que bajaban por el río Mao del lago Parime, a cuya restitución se añada la circunstancia de deshacer la fortaleza empezada a fabricar por la Nación Portuguesa cerca de la boca del río, y las ordenes para no impedir su navegacion a la española, e indemnizar los daños causados a

(83) MaCedo de SoAReS [81], pág. 178.

(84) Junta de límites: Comunicación a Gálvez, 5 de junio de 1783. En CAL MARTínEZ [44], pág. 181. 
esta por los comandantes portugueses de Barcelos y el Gran Pará y para sus Subalternos; sin perjuicio de especificar y arreglar en el Tratado de límites, los puntos necesarios para la línea divisoria en aquellas regiones (85).

Este artículo no fue incluido en el Tratado de 1777, aunque los españoles intentasen presionar a los portugueses. Por ejemplo, Gálvez ordena en septiembre al capitán general de Caracas, Unzeaga, que organice inmediatamente una expedición para expulsar a los portugueses del Parime (se recordará que la firma definitiva del Tratado lleva la fecha del 1 de octubre de 1777) (86). Tal vez por acuerdos entre las partes, la expedición no se llevó a cabo habiendo Unzaga recibido la contraorden de bloquear los preparativos. Esta orden fue despachada el 27 de diciembre, junto con diez ejemplares del Tratado de Paz (87).

Se cierra aquí la contienda portuguesa/española por el dominio sobre el Parime. Como escribe Nabuco en 1902, tal vez con un poco de ironía, después del Tratado de San Ildefonso, «la pretention ou Rio Branco n'était plus, aprés cela, soustenable de la part des Espagnols, et la question n'allá pas plus loin" (88).

(85) "Plan de Tratado" (Borrador sin firma). Fecha tentativa: después del 11 de junio de 1777. En Cal MarTínez [44], pág. 172.

(86) Gálvez: Orden al Capitán General Luis de Unzeaga y Amezaga 9 de noviembre de 1777. AGI, Caracas, 20.

(87) Cal MaRTínez [44], pág. 368.

(88) Nabuco [52], pág. 183. 


\section{ANEXOS CARTOGRÁFICOS}

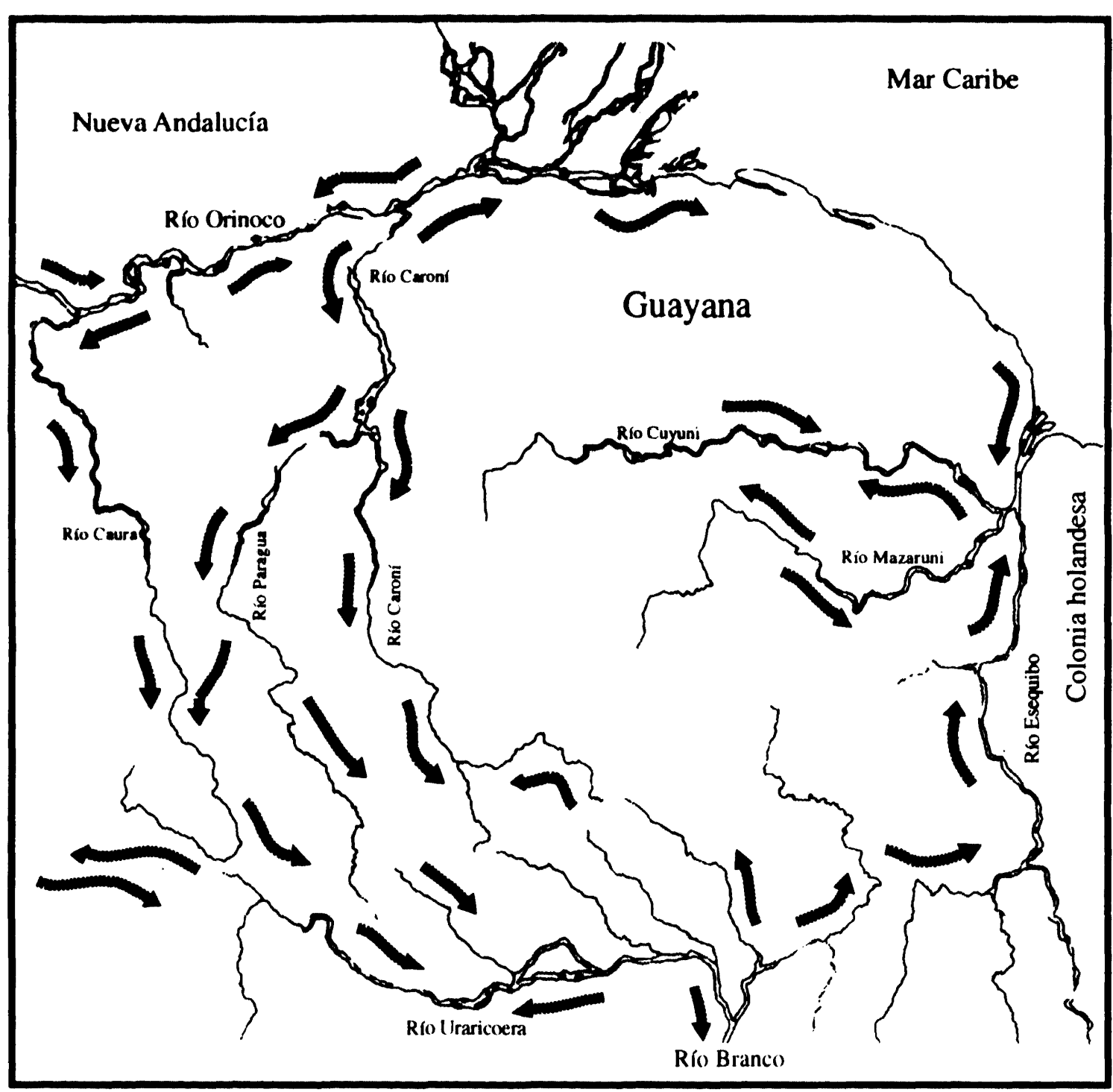

MAPA $n^{2}$ 1. Rutas de intercambio caribe: Orinoco-Esequibo (siglo XVIII). 


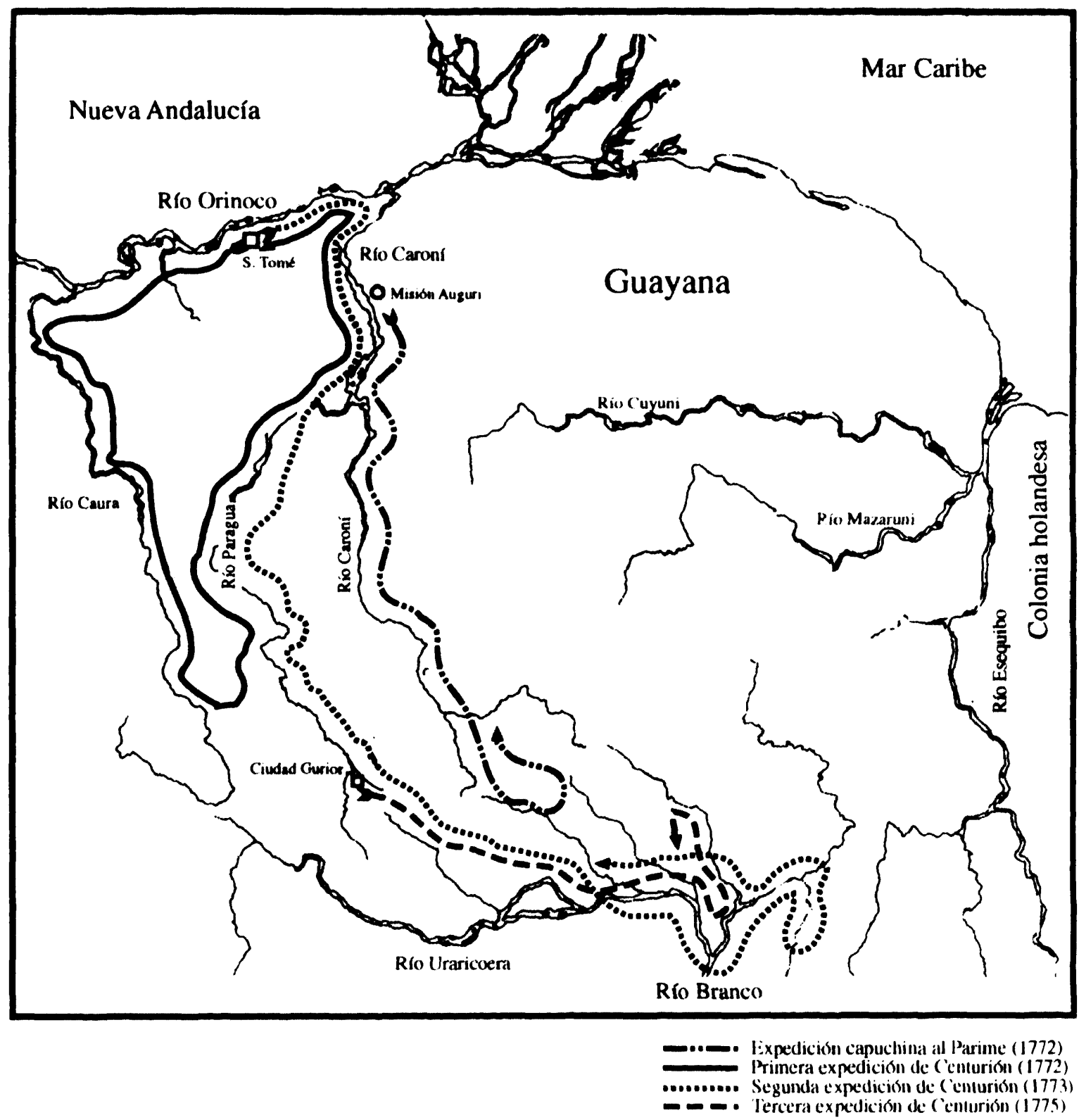

MaPA. $\mathrm{n}^{Q} 2$. Recorrido de las expediciones al Parime (1772-1775). 


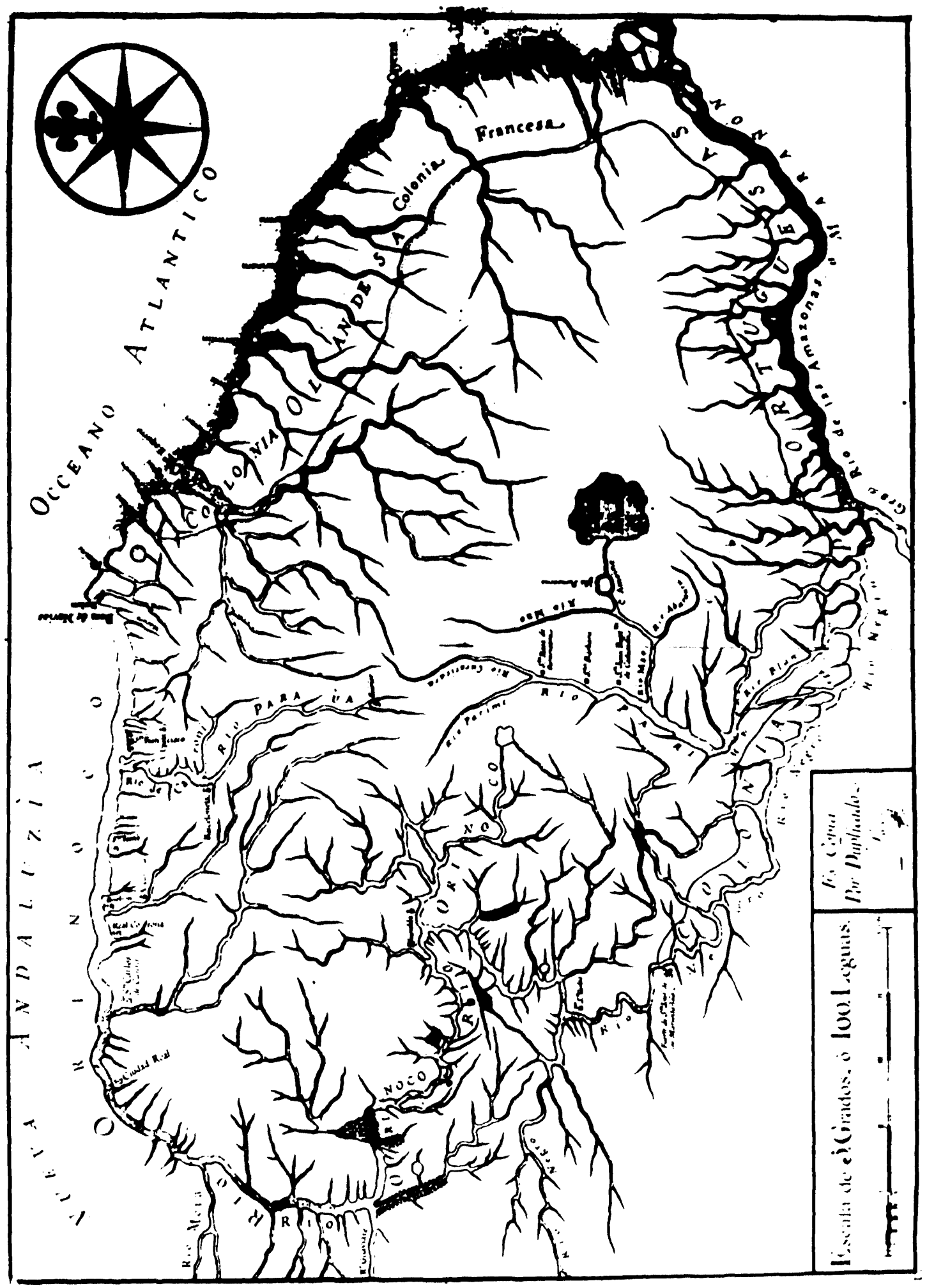

MAPA. $n^{\circ}$ 3. Mapa General de Guayana, Flores (1775). (AGI, Mapas y Planos, Venezuela, 183). 